\title{
EXHANCE-3: a cohort study of the exhalation delivery system with fluticasone for chronic sinusitis with or without nasal polyps*
}

\author{
Mandel R. Sher ${ }^{1}$, Gary C. Steven², J. Lewis Romett ${ }^{3}$, Gary Pien ${ }^{4}$, \\ Kerry LeBenger ${ }^{4}$, John C. Messina ${ }^{5}$, Jennifer L. Carothers ${ }^{5}$, \\ Ramy A. Mahmoud ${ }^{5}$, Per G. Djupesland 6 \\ ' Sher Allergy Specialist, Largo, FL, USA \\ ${ }^{2}$ Allergy, Asthma and Sinus Center, S.C., Greenfield, WI, USA \\ ${ }^{3}$ Colorado ENT and Allergy, Colorado Springs, CO, USA \\ ${ }^{4}$ Summit Medical Group, Berkeley Heights, NJ, USA \\ ${ }^{5}$ OptiNose US Inc, Yardley, PA, USA \\ ${ }^{6}$ Optinose AS, Oslo, Norway
}

Rhinology 58: 1, 25 - 35, 2020

https://doi.org/10.4193/Rhin 19.124

*Received for publication:

March 20, 2019

Accepted: October 14, 2019

\begin{abstract}
Background: Inhaled nasal corticosteroid sprays (INS) are often inadequate to treat chronic rhinosinusitis (CRS). The exhalation delivery system with fluticasone (EDS-FLU; XHANCE ${ }^{\oplus}$ ) may improve outcomes in CRS by increasing medication delivery to target superior/posterior anatomic sites. This study assessed safety and efficacy of EDS-FLU in a large population with moderate-tosevere CRS with or without nasal polyps (CRSwNP, CRSsNP).
\end{abstract}

Methods: Prospective, multicenter, 12-week, single-arm study of EDS-FLU $372 \mu \mathrm{g}$ twice daily (BID) at 38 U.S. sites. Safety was assessed by adverse-event evaluations, nasal endoscopy, and ocular examinations. Efficacy was serially assessed by outcomes including nasal endoscopy (Lund-Kennedy Score, polyp grade), patient- and physician-reported outcomes (22-item Sinonasal Outcome Test [SNOT-22]), study-defined surgical indicator assessment, and Patient Global Impression of Change (PGIC).

Results: 705 comparatively refractory subjects were enrolled, 603 CRSsNP and 102 CRSwNP [moderate-to-severely symptomatic; baseline SNOT-22 43, high rates of prior INS use (92.3\%) and/or prior surgery (27.5\%)]. More than $90 \%$ reported improvement on treatment by PGIC. SNOT-22 scores improved substantially and similarly in patients with NP (-23.7) and without NP (-24.4). Among patients with baseline Lund-Kennedy edema scores $>0,33.3 \%$ (CRSwNP) and 54.8\% (CRSsNP) had complete resolution of edema. In CRSwNP patients, $48 \%$ had polyp elimination in $\geq 1$ nostril, $63 \%$ had $\geq 1$-point improvement in polyp grade, mean bilateral polyp grade decreased from 2.9 to 1.6 , and study-defined surgical eligibility decreased. EDS-FLU was generally well tolerated, with a safety profile similar to conventional INS sprays when used to treat CRS.

Conclusion: EDS-FLU $372 \mu \mathrm{g}$ BID in the treatment of CRS with or without polyps was safe, well-tolerated, and produced substantial improvement across a broad range of both objective and subjective measures.

Key words: nasal cavity, nasal obstruction, nasal polyps, rhinitis, sinusitis

\section{Introduction}

Chronic rhinosinusitis (CRS) with or without nasal polyps (CRSwNP and CRSsNP, respectively) is the second most prevalent chronic health condition in the United States ${ }^{(1-3)}$. The economic burden of CRS (direct and indirect costs) was estimated at \$22 billion in the United States in $2014^{(4)}$.

CRS is associated with 4 cardinal defining symptoms: nasal con- 
gestion/obstruction, rhinorrhea, facial pain/pressure, and reduction/loss of smell ${ }^{(5,6)}$. Extra-sinonasal manifestations, including headache, sleep dysfunction, disordered mood (notably depression), and exacerbations of asthma and pulmonary disease, are common ${ }^{(5-8)}$. CRS is also associated with a large disease burden $^{(9,10)}$. Harm to quality of life (QoL) has been measured and is of similar magnitude to other serious chronic diseases such as congestive heart failure, chronic obstructive pulmonary disease, and Parkinson's ${ }^{(9)}$.

CRS is a syndrome characterized by inflammation affecting superior and posterior intranasal anatomical regions difficult to reach with conventional nasally inhaled topically-acting steroids $^{(11-13)}$. Inflammation at these sites can impair normal sinus and nasal cavity drainage and ventilation ${ }^{(14,15)}$. Complicating matters further are impaired mucociliary clearance, abnormal ventilation, and poor drainage of narrow crevices in the upper posterior nasal cavity and sinuses ${ }^{(11)}$. Nasal polyps (NP), commonly originating in the osteomeatal complex (OMC) region, can further exacerbate physical obstruction of paranasal sinus ventilation and clearance, and produce a variety of inflammatory cytokines ${ }^{(16-18)}$.

Oral corticosteroids are often effective in alleviating both symptoms and objective signs of CRS, but repeated or chronic use is constrained by many potentially serious risks, including avascular necrosis, infection, and venous thromboembolism ${ }^{(19-22)}$. Nevertheless, this observation shows that the molecular activity of corticosteroids is often effective in addressing CRS. To attempt to achieve this efficacy without systemic risk, most CRS treatment guidelines recommend first-line therapy with nasally administered, topically acting corticosteroids ${ }^{(5,6)}$. Topically acting corticosteroids are most often delivered by inhaled nasal spray. Target anatomic sites in CRS are the areas through which sinuses drain and ventilate, including the middle meatus and OMC (Iocated above the inferior turbinate, under the middle turbinate, and behind the uncinate process). Unfortunately, conventional nasal sprays often do not efficiently deposit the locally acting drug in disease sites beyond the nasal valve area, notably failing to reach the middle meatus/OMC, and are associated with drug loss to non-target sites (e.g., anterior "drip-out," or posterior loss to swallowing)(23-26). Poor targeting with conventional inhaled nasal sprays is believed to result in inadequate symptom control, limited polyp reduction when polyps are present, and annoying side effects (e.g., dysgeusia, loss of drug to drip-out or into the throat) ${ }^{(21-23,27-29)}$. The inadequate efficacy of conventional nasal spray steroids for treating CRS has been noted by multiple authors, and a large majority of patients with CRS report frustration with efficacy and low treatment satisfaction with these inhalation products ${ }^{(27-30)}$.
Several non-conventional approaches for corticosteroid delivery (typically at significantly higher doses than used for allergic rhinitis) have been studied, although none have previously been approved by the U.S. Food and Drug Administration (FDA). These include nasal drops and high-volume irrigation with a mixture of saline and a liquid steroid suspension. Some of these approaches may be effective; however, administration can be time consuming, typically relies on special head positions and procedures that can be difficult and uncomfortable for patients to consistently adhere to, and dose control may be challenging ${ }^{(31-33)}$. With irrigation in particular, $97.5 \%$ of the drug exits the nose or is swallowed, and patients may be bothered by post-irrigation rhinorrhea ${ }^{(31,32)}$. These factors create significant challenges to long-term compliance, with negative ramifications for efficacy ${ }^{(23,26)}$.

The FDA-approved exhalation delivery system with fluticasone (EDS-FLU; XHANCE ${ }^{\oplus}$ ) uses a novel exhalation delivery mechanism to deposit steroid superiorly and posteriorly in target regions affected by chronic inflammation in CRS, including the middle meatus/OMC (Figure 1) ${ }^{(36,37)}$. EDS-FLU comprises both an exhalation delivery system and a high-potency, low-bioavailability, topical corticosteroid (fluticasone) in an alcohol- and fragrance-free liquid formulation at a higher concentration than conventional over-the-counter and prescription inhaled nasal spray products ${ }^{(37-41)}$. EDS-FLU uses a novel mechanism and exposes significantly different anatomic locations to active medication compared with conventional inhaler sprays and has been studied extensively. Evidence from multiple published studies, including a randomized pharmacokinetic study, two large randomized controlled trials (RCTs), and one long-term prospective, single-arm study, have characterized its efficacy and safety and demonstrated that EDS-FLU is not bioequivalent to comparable doses of conventional fluticasone nasal spray (Flonase $\left.{ }^{\circledast}\right)^{(37-41)}$. The objective of this study was to evaluate patient experience by assessing the safety and efficacy of EDS-FLU $372 \mu \mathrm{g}$ twice daily (BID) in a large and relatively heterogenous population with moderate-to-severe CRSwNP or CRSsNP. This study expands on prior knowledge by prospectively evaluating the highest dose of EDS-FLU in a substantially larger population, permitting evaluation of less common events and expanding the generalizability of results.

\section{Materials and methods}

This prospective, 12-week, single-arm, repeat nasal endoscopy study was conducted in 38 centers in the U.S. The first patient was enrolled October 3, 2013, and the last completed on February 2, 2015. Eligible participants were $\geq 18$ years of age with either a history of CRSWNP (determined by nasal endoscopy) or CRSsNP, in which case they had to be currently experiencing 2 or more of the diagnostically defining symptoms of CRS, of which 


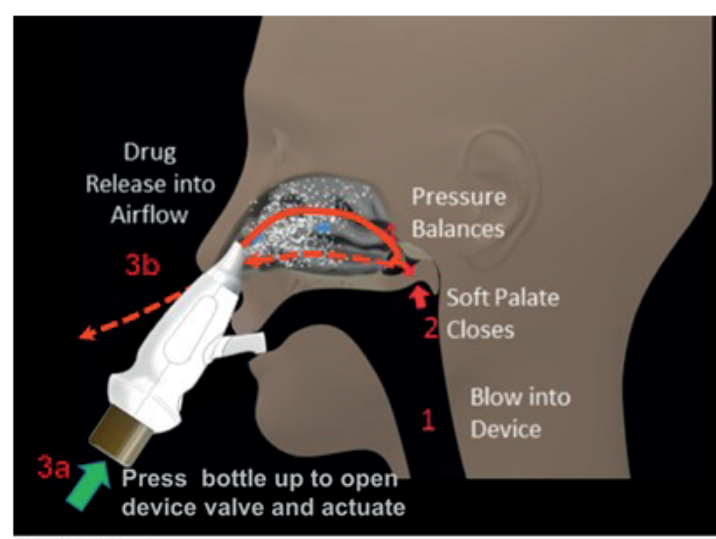

Sagittal plane
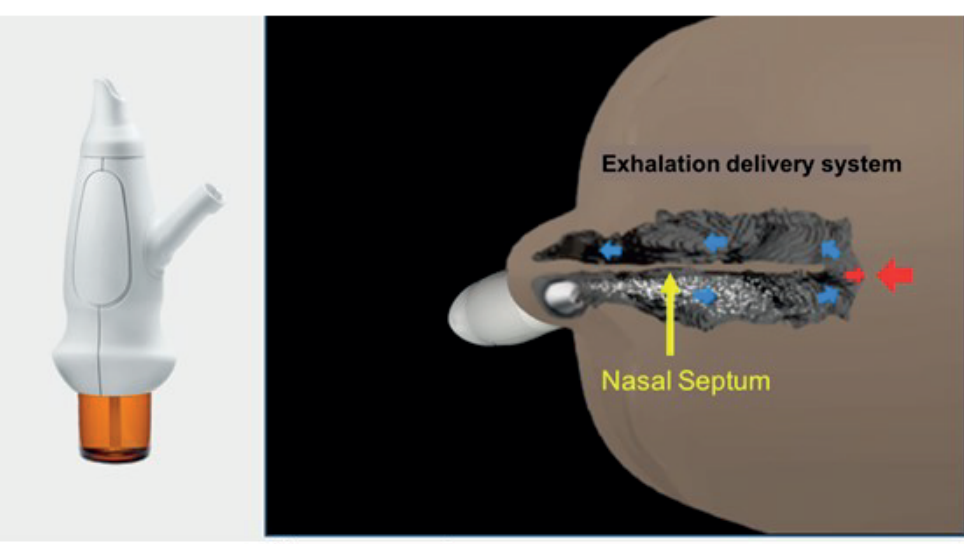

Transverse plane

Figure 1. Exhalation Delivery System (EDS) mechanism of action. The EDS has a flexible mouthpiece and a sealing nosepiece. The nosepiece is uniquely shaped to seal at the nostril in order to transfer pressure from the oral cavity, avoid obstruction by compression of soh tissue, and stent/expand the upper part of the nasal valve. Exhalation through the EDS: 1) creates an airtight seal of the soft palate, isolating the nose from the mouth and lungs, 2) transfers proportional pressure into the nose, and 3) helps "float" medication around obstructions to deposit in high/deep sites throughout the nasal labyrinth, such as the OMC. "Positive-pressure" delivery expands passages narrowed by inflammation (versus negative pressure delivery, "sniffing"). The transferred pressure is proportional to varying exhalation force, counterbalancing pressure across the soh palate. This assures a patent communication behind the nasal septum, allowing air to escape through the opposite nostril. Use is simple and quick. A patient inserts the nosepiece into one nostril and starts blowing through the mouthpiece. This elevates and seals the soft palate, as with inflating a balloon, separating the oral and nasal cavities. The patient completes use by pressing the bottle to actuate. This causes a coordination-reducing valve to release the exhaled breath concurrently with aerosol spray in a "burst" of naturally humidified air that escapes through the contralateral nostril after depositing the drug particles ${ }^{(59)}$.

1 had to be congestion or rhinorrhea, lasting $\geq 3$ months, and receive a diagnosis from a specialist after endoscopic examination. Defining symptoms included nasal congestion/obstruction, rhinorrhea, facial pain/pressure, and reduction/loss of smell. Participants with comorbid asthma or COPD had to be stable at entry (no exacerbations within 3 months of screening). Inhaled pulmonary corticosteroid use was limited to stable doses $\leq 1000$ $\mu \mathrm{g} /$ day of beclomethasone (or equivalent) for at least 3 months prior to screening. Treatment with any other intranasal corticosteroid or an orally inhaled corticosteroid was not permitted, except for the above-mentioned drugs and doses for asthma and COPD.

Exclusion criteria included known nasal septum perforation; $>1$ episode of frank nasal bleeding in the month prior to screening; evidence of significant mucosal injury, ulceration, or erosion at screening; history of sinonasal surgery within 6 months; or planned sinonasal surgery during the study period.

A pretreatment phase of up to 7 days preceded a screening visit. Following screening and selection, all participants received EDSFLU $372 \mu \mathrm{g}$ BID. Because an objective of this study was to assess safety in a broad CRS population with and without polyps, all patients received the highest dose evaluated in dose-ranging $\mathrm{RCTs} \mathrm{s}^{(39,40)}$. Safety was proactively assessed at Months 1, 2, and 3: visits at Months 1 and 3, and contact at Month 2. Adverse events
(AEs) were either reported spontaneously, during contact at Month 2 for AE evaluation, or identified during scheduled nasal endoscopy at Months 1 and 3 or scheduled ocular exams at Month 3. Ocular evaluations included intraocular pressure (IOP) measurement and slit-lamp examination by an ophthalmologist to assess for cataracts. Efficacy was objectively assessed by physician specialists directly observing the nasal cavity by nasal endoscopy at baseline, at subsequent scheduled visits, and by patient report at screening and after 1 and 3 months of treatment.

Efficacy was measured by 22-item Sino-Nasal Outcome Test (SNOT-22), a widely used, disease-specific, patient-reported instrument assessing QoL, functioning, and symptoms. SNOT-22 is validated in CRS, with each item scored from 0 (no problem) to 5 (as bad as can be), producing a total scoring range of 0 to $110^{(43)}$. The minimal clinically important difference (MCID) has been reported to be 8.9-12(44,45). Additionally, in participants with NP at baseline, a modified Lildholdt NP grading scale was used to assess change in polyp grade with treatment. Polyp assessment with this scale is not a measure of total polyp mass or bulk; rather, it non-linearly evaluates extent of observable polyp tissue in a single dimension (vertical) against fixed anatomic landmarks. In this study, possible scores ranged from 0 (no polyps observed) to 3 (polyp tissue extends below the inferior border of the inferior turbinate) on each side ${ }^{(46)}$. Surgical-indica- 


\begin{tabular}{|c|c|c|c|}
\hline Characteristics & CRS with NP ( $N=102)$ & CRS without NP ( $N=603)$ & Total enrolled $(\mathbf{N}=705)$ \\
\hline Age, mean (SD) & $45.2(13.66)$ & $45.4(13.73)$ & $45.3(13.71)$ \\
\hline Male sex, n (\%) & $56(54.9)$ & $246(40.8)$ & $302(42.8)$ \\
\hline White race, $\mathrm{n}(\%)$ & $91(89.2)$ & $461(76.5)$ & $552(78.3)$ \\
\hline Prior corticosteroid use for CRS (within last $10 \mathrm{y})^{*}, \mathrm{n}(\%)$ & $99(97.1)$ & $549(91.5)$ & $648(92.3)$ \\
\hline Mometasone furoate, $\mathrm{n}(\%)$ & $58(56.9)$ & $247(41.2)$ & $305(43.4)$ \\
\hline Fluticasone propionate, n (\%) & $82(80.4)$ & $403(67.2)$ & $485(69.1)$ \\
\hline Intranasal steroid use in last $30 \mathrm{~d}^{+}, \mathrm{n}(\%)$ & $62(60.8)$ & $213(35.3)$ & $275(39.0)$ \\
\hline Bilateral endoscopic NP score, mean (SD) & $2.9(1.2)$ & - & - \\
\hline Lund-Kennedy edema score, mean (SD) & $2.1(1.2)$ & $1.7(1.4)$ & $1.8(1.4)$ \\
\hline SNOT-22 total score, mean (SD) & $43.8(19.2)$ & $43.2(19.5)$ & $43.3(19.5)$ \\
\hline $\begin{array}{l}\text { Prior sinus surgery (with or without polyp removal) or } \\
\text { polypectomy surgery, } \mathrm{n}(\%)\end{array}$ & $61(59.8)$ & $155(25.7)$ & $216(30.6)$ \\
\hline
\end{tabular}

*Prior corticosteroid use for CRS refers to use of any corticosteroid, including oral or intranasal, but only for CRS (eg, not for asthma or another purpose) $;{ }^{\dagger}$ Intranasal steroid use refers specifically to use of an intranasal steroid.

tor assessment criteria for participants with CRSwNP required all the following: moderate congestion for $\geq 3$ months; at least moderate symptoms despite use of topical steroids at conventional doses for $\geq 6$ weeks; at least moderate symptoms despite use (or previous use) of saline lavage for $\geq 6$ weeks; and NP grade $\geq 2$ in at least 1 nostril. Criteria for participants with CRSsNP required all of the following: moderate severity of $\geq 2$ core symptoms (congestion/blockage, nasal discharge, facial pain/pressure, reduction/loss of smell) for $\geq 3$ months, with 1 symptom required to be congestion/obstruction or nasal discharge; purulent mucus or obstructive edema or mucus in the middle meatus or ethmoid region on endoscopic examination; at least moderate symptoms despite use of topical steroids at conventional doses for $\geq 6$ weeks; and at least moderate symptoms despite use (or previous use) of saline lavage for $\geq 6$ weeks.

Efficacy was also evaluated with the Lund-Kennedy endoscopic scoring system, a validated approach to measurement of sinonasal cavity inflammatory disease, at each nasal endoscopic examination ${ }^{(47)}$. Lund-Kennedy scores include 5 components (polyposis, discharge, edema, scarring, and crusting), each graded on an ordinal scale from 0-2 for each side. Higher scores indicate worse disease. Efficacy assessments were also obtained directly from treated subjects using the Patient Global Impression of Change (PGIC). The PGIC scale is the most commonly used anchor-based method of assessing clinically important change based on patient input ${ }^{(48,49)}$. The PGIC is particularly suited to capturing clinically meaningful change that makes a difference to the patient; it consists of 1 question rated on a 7-point Likert scale $^{(49,50)}$. In addition, a medical evaluation questionnaire assessed patient-reported ease of use, comfort of use, dysgeusia, and loss of drug to drip-out from the nose and down the back of the throat for EDS-FLU and the most recently used prior intranasal steroid.

Efficacy and safety data were summarized using descriptive statistics. End-of-study assessments included the last recorded information at Month 1 or Month 3 regardless of whether the participant completed the study. Descriptive statistics for continuous variables included the number of observations, mean, standard deviation (SD), median, minimum, and maximum, and for descriptive statistics included participant counts and percentages.

\section{Results}

A total of 966 participants were screened, and 705 enrolled and received study drug (102 CRSwNP, 603 CRSsNP). Overall, 149 (27.5\%) had a history of sinus surgery. Of 705 receiving study drug, 601 (85.2\%) completed the study and 104 (14.8\%) discontinued prematurely. Reasons for discontinuation included loss to follow-up (43 participants; 6.1\%), AEs (22 participants, $3.1 \% ; 14$ deemed related by the study investigator), withdrawal of consent (20 participants; $2.8 \%$ ), withdrawal due to protocol deviation (12 participants; $1.7 \%$ ), other reasons (4 participants; $0.6 \%$ ), and lack of efficacy (3 participants; $0.4 \%$ ). Baseline characteristics are reported in Table 1.

At Month 1, mean SNOT-22 total scores improved substantially from baseline, with similar improvement in participants with CRSwNP (-20.3) and CRSsNP (-20.8). SNOT-22 scores improved more with longer duration of treatment through Month 3 (CRSwNP, -23.7; CRSsNP, -24.4) (Table 2). Improvement in SNOT- 
Table 2. Mean and median SNOT-22 total and subscale scores over time.

\begin{tabular}{|c|c|c|c|}
\hline & Baseline & 1 Month & 3 Month \\
\hline \multicolumn{4}{|l|}{ Total SNOT-22 } \\
\hline \multicolumn{4}{|l|}{ CRS with NP } \\
\hline $\mathrm{N}$ & 101 & 95 & 92 \\
\hline Mean (SD) & $43.8(19.19)$ & $23.1(17.61)$ & $18.7(16.75)$ \\
\hline Median (Min, Max) & $45.0(7,91)$ & $18.0(1,77)$ & $12.5(0,72)$ \\
\hline \multicolumn{4}{|l|}{ CRS without NP } \\
\hline $\mathrm{N}$ & 600 & 554 & 504 \\
\hline Mean (SD) & $43.2(19.54)$ & $22.5(17.04)$ & $18.5(16.95)$ \\
\hline Median (Min, Max) & $42.5(0,110)$ & $19.0(0,85)$ & $14.0(0,80)$ \\
\hline \multicolumn{4}{|c|}{ Rhinologic Symptoms Subscale } \\
\hline \multicolumn{4}{|l|}{ CRS with NP } \\
\hline $\mathrm{N}$ & 101 & 96 & 92 \\
\hline Mean (SD) & $19.0(6.80)$ & $10.1(7.03)$ & $8.8(6.86)$ \\
\hline Median (Min, Max) & $19.0(1,34)$ & $9.0(0,29)$ & $7.0(0,28)$ \\
\hline \multicolumn{4}{|l|}{ CRS without NP } \\
\hline $\mathrm{N}$ & 601 & 555 & 505 \\
\hline Mean (SD) & $16.3(6.33)$ & $8.8(5.94)$ & $7.4(6.27)$ \\
\hline Median (Min, Max) & $16.0(0,35)$ & $8.0(0,28)$ & $6.0(0,30)$ \\
\hline \multicolumn{4}{|c|}{ Ear and Facial Symptoms Subscale } \\
\hline \multicolumn{4}{|l|}{ CRS with NP } \\
\hline $\mathrm{N}$ & 102 & 96 & 92 \\
\hline Mean (SD) & $5.2(4.21)$ & $2.6(3.18)$ & $2.0(2.85)$ \\
\hline Median (Min, Max) & $4.0(0,16)$ & $1.0(0,16)$ & $1.0(0,13)$ \\
\hline \multicolumn{4}{|l|}{ CRS without NP } \\
\hline $\mathrm{N}$ & 602 & 555 & 507 \\
\hline Mean (SD) & $6.5(4.42)$ & $3.1(3.44)$ & $2.5(3.28)$ \\
\hline Median (Min, Max) & $6.0(0,20)$ & $2.0(0,18)$ & $1.0(0,20)$ \\
\hline \multicolumn{4}{|c|}{ Sleep Function Subscale } \\
\hline \multicolumn{4}{|l|}{ CRS with NP } \\
\hline $\mathrm{N}$ & 102 & 95 & 92 \\
\hline Mean (SD) & $6.3(4.50)$ & $3.4(3.73)$ & $2.4(3.64)$ \\
\hline Median (Min, Max) & $6.0(0,15)$ & $2.0(0,14)$ & $0.5(0,15)$ \\
\hline \multicolumn{4}{|l|}{ CRS without NP } \\
\hline $\mathrm{N}$ & 601 & 556 & 508 \\
\hline Mean (SD) & $6.6(4.35)$ & $3.4(3.81)$ & $2.9(3.66)$ \\
\hline Median (Min, Max) & $6.0(0,15)$ & $2.0(0,15)$ & $1.0(0,15)$ \\
\hline \multicolumn{4}{|c|}{ Psychological Function Subscale } \\
\hline \multicolumn{4}{|l|}{ CRS with NP } \\
\hline $\mathrm{N}$ & 102 & 96 & 92 \\
\hline Mean (SD) & $9.2(6.84)$ & $4.6(5.67)$ & $3.6(5.16)$ \\
\hline Median (Min, Max) & $8.5(0,29)$ & $2.0(0,26)$ & $1.0(0,24)$ \\
\hline \multicolumn{4}{|l|}{ CRS without NP } \\
\hline $\mathrm{N}$ & 601 & 556 & 509 \\
\hline Mean (SD) & $9.5(6.93)$ & $4.7(5.44)$ & $3.8(5.09)$ \\
\hline Median (Min, Max) & $8.0(0,30)$ & $3.0(0,30)$ & $2.0(0,30)$ \\
\hline
\end{tabular}


Table 3. Mean change from baseline in SNOT-22 subscale scores.

\begin{tabular}{|c|c|c|}
\hline & Baseline Mean (SD) & $\begin{array}{c}\text { Change at } 3 \text { Months } \\
\text { Mean (SD) }\end{array}$ \\
\hline & CRSwNP N=101 & CRSwNP N=92 \\
\hline & CRSSNP N=600 & CRSsNP N=504 \\
\hline \multicolumn{3}{|l|}{ Total SNOT-22 } \\
\hline CRS with NP & $43.8(19.19)$ & $-23.7(19.95)$ \\
\hline CRS without NP & $43.2(19.54)$ & $-24.4(19.93)$ \\
\hline \multicolumn{3}{|c|}{$\begin{array}{l}\text { Rhinologic } \\
\text { Symptoms Subscale }\end{array}$} \\
\hline CRS with NP & $19.0(6.80)$ & $-10.0(8.29)$ \\
\hline CRS without NP & $16.3(6.33)$ & $-9.1(7.46)$ \\
\hline \multicolumn{3}{|c|}{$\begin{array}{l}\text { Ear and Facial } \\
\text { Symptoms Subscale }\end{array}$} \\
\hline CRS with NP & $5.2(4.21)$ & $-2.7(3.48)$ \\
\hline CRS without NP & $6.5(4.42)$ & $-3.9(4.17)$ \\
\hline \multicolumn{3}{|l|}{$\begin{array}{l}\text { Sleep Function } \\
\text { Subscale }\end{array}$} \\
\hline CRS with NP & $6.3(4.50)$ & $-3.8(4.58)$ \\
\hline CRS without NP & $6.6(4.35)$ & $-3.6(4.32)$ \\
\hline \multicolumn{3}{|c|}{$\begin{array}{l}\text { Psychological Func- } \\
\text { tion Subscale }\end{array}$} \\
\hline CRS with NP & $9.2(6.84)$ & $-5.2(5.84)$ \\
\hline CRS without NP & $9.5(6.93)$ & $-5.4(6.36)$ \\
\hline
\end{tabular}

CRSwNP, chronic rhinosinusitis with nasal polyps; CRSsNP, chronic rhinosinusitis without nasal polyps.

22 total scores exceeded the MCID of $8.9-12^{(44,45)}$ and was not a function of isolated subscales; substantial improvement was reported on all subscales by patients with or without NP (Table 3 ).

The subset of patients with NP at study entry had notably lower baseline polyp grades (implying more superiorly/posteriorly located polyp tissue) than typically observed in CRSwNP treatment trials (mean baseline polyp grade 2.9) ${ }^{(22,51,52)}$. Nevertheless, polyp patients had substantial improvement in polyp grade with treatment (mean decrease in bilateral NP scores at Month 1 and Month 3 of -0.8 and -1.3 , respectively). The percentage of patients endoscopically observed to have polyp elimination in at least 1 nostril increased with longer treatment duration (Figure 2a). Among those completing 3 months of treatment, $48 \%$ with NP at baseline had NP elimination in at least 1 nostril, and $63 \%$ had a $\geq 1$-point improvement in polyp grade (Figure $2 b$ ). At screening, 42\% (43 of 102) and 6\% (36 of 603) of patients with and without NP, respectively, met indicator criteria for surgical eligibility. By Month 1, the proportion meeting surgicalindicator criteria decreased to $24.2 \%$ and $5.4 \%$ in those with and without NP, respectively, and continued to decrease with longer treatment duration, reaching $19.1 \%$ and $2.2 \%$, respectively (corresponding to reductions of $54.5 \%$ and $63.3 \%$ ), at 3 months.
A

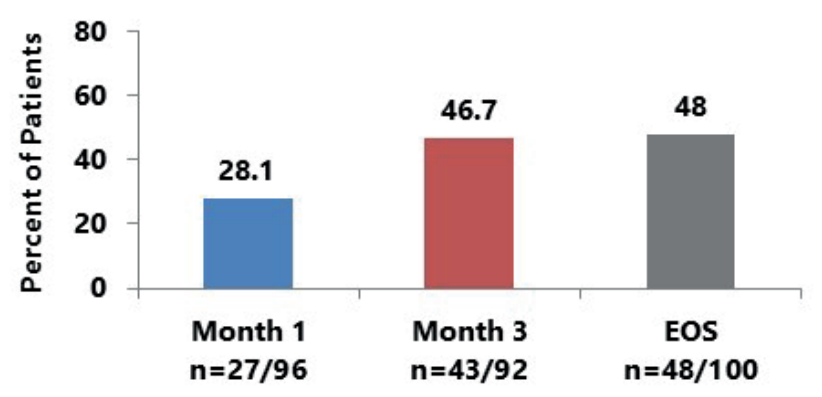

B

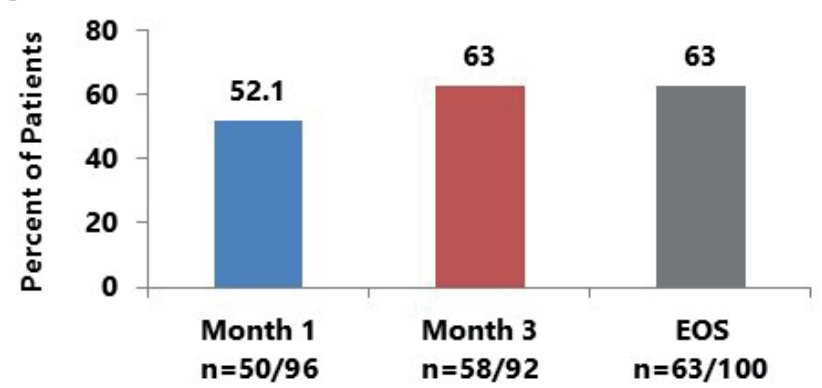

Figure 2. (A) Polyp elimination in at least 1 nostril. (B) 1-point improvement in bilateral NP grade. Month 3 includes patients who completed the study. EOS (end of study) assessments include the last recorded post-baseline information regardless of study completion.

The large subgroup of patients currently using a conventional inhaled steroid nasal spray at study entry $(n=275)$ were analyzed to determine if benefits were reduced compared with patients who were not. The benefit of EDS-FLU on subjective and objective outcomes was comparable for patients switched directly from a conventional steroid nasal spray or not. Sino-Nasal Outcome Test (SNOT-22) scores decreased from baseline for 'switchers' (52.3\%) and 'non-switchers' (42.9\%). SNOT-22 scores decreased from baseline for $52.3 \%$ of 'switchers' and for $42.9 \%$ of 'non-switchers'. Patients reported improvements in PGIC ( $85.7 \%$ of 'switchers', and $91.9 \%$ of 'non-switchers').

Lund-Kennedy total endoscopic scores for sinonasal inflammatory pathology decreased considerably following 1 and 3 months of EDS-FLU treatment, with incremental improvement between Month 1 and Month 3. Improvements in all 4 nonpolyp domains were similar in patients with or without NP. The domains of edema and discharge were the primary sources of improvement, with limited contributions from the crusting and scarring domains, both of which were near normal at baseline (Table 4). At Month 3, among participants with baseline LundKennedy edema scores $>0$, EDS-FLU treatment was associated with complete resolution of edema in $33.3 \%$ of patients with CRSwNP and $54.8 \%$ with CRSsNP.

By Month 3, approximately $90 \%$ of participants reported symptom improvement as assessed by PGIC, with approximately $70 \%$ 
Table 4. Mean change from baseline in Lund-Kennedy and NP scores.

\begin{tabular}{|c|c|c|c|}
\hline & $\begin{array}{l}\text { Baseline } \\
\text { Mean (SD) }\end{array}$ & $\begin{array}{c}\text { Mean (SD) } \\
\text { Change at } 1 \\
\text { Month }\end{array}$ & $\begin{array}{c}\text { Mean (SD) } \\
\text { Change at } 3 \\
\text { Months }\end{array}$ \\
\hline & $\begin{array}{l}\text { CRSwNP } \\
N=102 \\
\text { CRSsNP } \\
N=603\end{array}$ & $\begin{array}{c}\text { CRSwNP } \\
\begin{array}{c}\mathrm{N}=96 \\
\text { CRSsNP } \\
\mathrm{N}=554\end{array}\end{array}$ & $\begin{array}{c}\text { CRSwNP } \\
\mathrm{N}=92 \\
\text { CRSsNP } \\
\mathrm{N}=505\end{array}$ \\
\hline \multicolumn{4}{|l|}{ Edema } \\
\hline CRS with NP & $2.1(1.20)$ & $-0.8(1.24)$ & $-0.9(1.39)$ \\
\hline CRS without NP & $1.7(1.37)$ & $-0.7(1.26)$ & $-1.0(1.43)$ \\
\hline \multicolumn{4}{|l|}{ Discharge } \\
\hline CRS with NP & $1.8(1.04)$ & $-0.6(1.23)$ & $-0.6(1.20)$ \\
\hline CRS without NP & $1.3(1.05)$ & $-0.5(1.13)$ & $-0.6(1.21)$ \\
\hline \multicolumn{4}{|l|}{ Crusting } \\
\hline CRS with NP & $0.4(0.92)$ & $-0.1(0.83)$ & $-0.0(0.94)$ \\
\hline CRS without NP & $0.2(0.57)$ & $0.1(0.64)$ & $0.0(0.65)$ \\
\hline \multicolumn{4}{|l|}{$\begin{array}{l}\text { Scarring/Adhe- } \\
\text { sions }\end{array}$} \\
\hline CRS with NP & $0.1(0.50)$ & $-0.1(0.51)$ & $-0.1(0.46)$ \\
\hline CRS without NP & $0.1(0.31)$ & $-0.0(0.22)$ & $-0.0(0.25)$ \\
\hline \multicolumn{4}{|l|}{ NP } \\
\hline CRS with NP & $2.8(1.01)$ & $-0.8(1.14)$ & $-1.3(1.33)$ \\
\hline
\end{tabular}

CRSwNP, chronic rhinosinusitis with nasal polyps; CRSsNP, chronic rhinosinusitis without nasal polyps.

reporting "much" or "very much" improvement. Rates of symptom improvement during the study were similar for participants with or without NP (Figure 3).

On the medical evaluation questionnaire, 543 of 601 participants (90.3\%) reported EDS-FLU to be somewhat or very easy to use, and 495 (82.4\%) reported EDS-FLU to be somewhat or very comfortable to use at the Month 3 visit. The majority of participants reported minimal or no drip from the nose (75\%) and minimal or no drip down the back of the throat (88\%). Compared with their most recent previous intranasal steroid, with EDS-FLU $62 \%$ of patients reported less or much less drip out of the nose, and $69 \%$ reported less or much less drip down the back of throat.

The majority of reported AEs were local (not systemic), mild in severity, and resolved spontaneously with continued use of EDS-FLU. The most common AEs ( $>5 \%)$ included nasal mucosal disorder (10.2\%), spontaneously reported epistaxis (6.8\%), nervous system disorder (5.7\%), and nasal septum disorder (5.5\%). A nasal septal perforation was observed post-baseline in 2 study participants (0.3\%). Ophthalmic examinations revealed no evidence of a trend toward increasing IOP during treatment, and no subcapsular cataracts (believed to be associated with systemic corticosteroid exposure) were identified during follow-up.

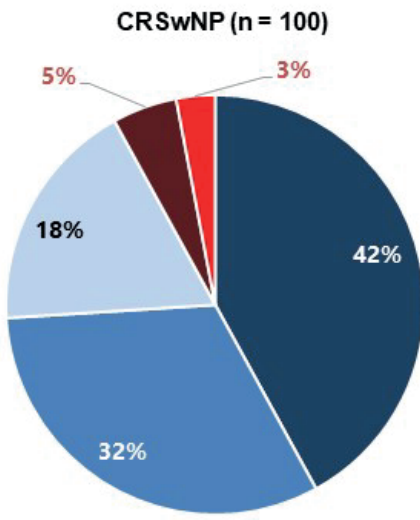

CRSsNP ( $n=577)$

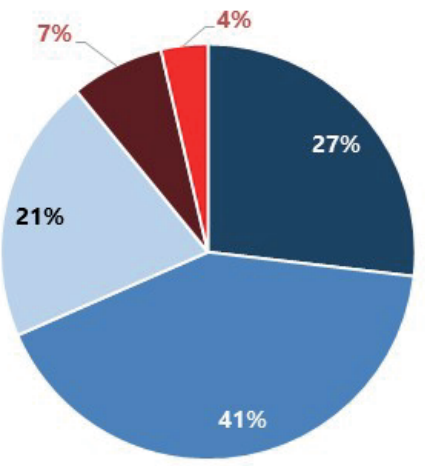

- Very much improved

- Much improved

Minimally improved

- No change
Worse

Figure 3. Patient Global Impression of Change: symptoms after treatment (end of study).

\section{Discussion}

EDS-FLU uses a novel delivery approach, targeting placement of a well-characterized, widely used topical corticosteroid in deep nasal locations not easily accessed by conventional inhaled nasal sprays. The EDS uses a unique mechanism of action to enable reliable and consistent steroid deposition superiorly/ posteriorly in the nasal cavity, and is therefore potentially useful for patients where this deposition profile may be beneficial. This 12-week study characterizes the safety and efficacy of EDS-FLU in a large and comparatively diverse moderate-to-severe patient cohort with CRS (with or without nasal polyps), more than $90 \%$ of whom previously used corticosteroids and/or had prior sinonasal surgery. The EDS-FLU dose in this study was $372 \mu \mathrm{g} \mathrm{BID,}$ comparable to the EU-approved dose of fluticasone drops but higher than the equivalent dose studies of mometasone conventional inhaled spray ${ }^{(51,52)}$. This allowed safety assessment at the highest approved dose, though in pivotal trials the efficacy of a lower dose (186 $\mu \mathrm{g}$ BID; comparable to the studied mometasone dose) was reasonably similar ${ }^{(39,40)}$.

Previously published RCTs in patients with CRSwNP showed that EDS-FLU improves all four defining symptoms of CRS (congestion, rhinorrhea, facial pain/pressure, hyposmia), reduces NP grade, eliminates up to $\approx 30 \%$ of polyps in $\geq 1$ nostril after 24 weeks of treatment, and results in SNOT-22 improvement similar 
in magnitude to reported improvement with endoscopic sinus surgery ${ }^{(39,40)}$. This trial expands the evidence base and provides information from a large and diverse cohort enrolled with less restrictive entry criteria than typical for controlled pivotal trials. Importantly, this study population comprised patients likely to be real-world candidates for EDS-FLU treatment (patients who continue to have symptoms despite prior use of conventional inhaled nasal steroids and/or history of sinus surgery).

In this study, patients with or without NP at baseline experienced substantial improvements in symptoms, QoL, functioning, and objective evidence of sinonasal inflammatory disease. Improvements measured by SNOT-22 were comparable in magnitude for participants with or without NP, and all SNOT-22 subscales improved. The magnitude of improvement substantially exceeds previously reported clinically significant thresholds of 8.9-12 points and is comparable to the magnitude of improvement reported following endoscopic sinus surgery, although the treatment populations may differ ${ }^{(44,45)}$.

Symptomatic improvement correlated with objective improvement in sinonasal inflammation, assessed using serial LundKennedy endoscopic scoring. In particular, nasal edema and discharge, both elevated at baseline, showed improvement with EDS-FLU. This substantiates that the improved intranasal deposition of anti-inflammatory drug with EDS-FLU is associated with improved symptoms and QoL.

PGIC values $\geq 6$ ("much" or "very much" improvement) have been found to equate to a noticeable, worthwhile change that is meaningful to the patient ${ }^{(48,49)}$. Despite the relatively refractory population entering the current study, a very high proportion of participants reported improvement at 3 months ( $90 \%$ improved; 73\% "much" or "very much" improved). This finding is consistent with prior research ${ }^{(39-41)}$ and indicates that EDS-FLU-associated improvement is clinically meaningful and provides benefits to a large proportion of patients in this relatively refractory population. There were treatment non-responders in this study; their presence is consistent with prior evidence that not all CRS is susceptible to corticosteroid treatment. Patients who are refractory to oral steroids are not expected to benefit from even a radical change in topical corticosteroid delivery; however, it is notable that the large subgroup that was symptomatic at baseline and switched directly to EDS-FLU from a prior conventional inhaled nasal steroid reported comparably large improvement in multiple efficacy measures. This supports the different activity of EDS-FLU from conventional inhaled nasal steroids and the potential value for patients who are inadequately controlled by conventional nasal sprays.
Ease of use is an important consideration when relying on patients to employ a new mental model, as with exhalation delivery. Medical evaluation questionnaires show that EDS-FLU was perceived by more than $80 \%$ of patients as easy and comfortable to use, and that the exhalation mechanism of delivery observably reduced drug loss due to anterior and posterior drip.

\section{Current CRS treatment guidelines recommend topical nasal} corticosteroids, usually administered using a conventional inhalation nasal spray, as first-line therapy ${ }^{(5,6)}$. Alternate nonconventional delivery methods, mostly gravity-assisted, such as nasal drops and locally compounded high-volume medicated irrigation, have been studied to varying degrees but are subject to serious practical challenges, particularly when long-term compliance is necessary ${ }^{(23,26,31-33)}$. Considerations include difficulty with training and optimal head positions, control of local dose exposure, off-target gastrointestinal or lung exposure, time and effort associated with use, discomfort, poor dose control, and insurance coverage. For patients with milder symptoms or larger (easier to access) polyps, conventional inhaled nasal sprays offer some symptom benefit and have been shown to reduce polyp size ${ }^{(51-54)}$. Interestingly, baseline polyp grade scores in registration studies for nasal spray mometasone ${ }^{(51,52,54)}$ (and of EDS-FLU) ${ }^{(39,40)}$ ranged from 3.6 to 4.3 ; after 4 months of treatment, scores remained higher than or similar to the baseline polyp scores in this study (2.9). Different anatomic barriers to delivering drug to polyp tissue of different grades and the nonlinear nature of the grading scale both accentuate the inappropriateness of comparing 'absolute' numerical changes across trials and the importance of considering baseline scores ${ }^{(55)}$. Indeed, several trials with conventional inhaled nasal sprays suggest that improvement in bilateral polyp grade (on a 0-6 scale) appears to plateau at an average score of $\approx 3$ and does not improve further with longer treatment ${ }^{(22,51,52)}$. Furthermore, data from a longerterm study of conventional nasal spray suggests that smaller polyps may experience regrowth during such treatment ${ }^{(22)}$. This is not surprising because conventional inhaled steroid sprays are capable of reliably delivering locally-acting medication to the surface of large polyps that protrude far inferiorly or anteriorly, but do not continue to deliver steroid to the surface of polyps as they regress into the region of the OMC, where inflammation and associated polypoid tissue continue to obstruct sinuses ${ }^{(24-26)}$. In this study, CRSwNP patients had a baseline polyp grade of only 2.9, and EDS-FLU produced a continually decreasing polyp grade, reaching 1.6 after 3 months; $63.0 \%$ of participants were observed to have $\geq 1$-point improvement in NP score, and $46.7 \%$ of patients experienced complete polyp elimination in at least 1 nostril by study end. This progressive decrease in polyp gradeand elimination in some cases-is physiologically consistent with reliable long-term deposition of steroid on inflamed tissue, including the site of origin of most polyps in the OMC region. 
We are unaware of similar improvement previously reported with other topical medical therapies.

Surgery is often offered to CRS patients who fail medical therapy ${ }^{(5,6,56,57)}$. Revision surgery is also performed in a substantial minority of patients whose symptoms are not adequately addressed by the initial procedure and subsequent medical therapy ${ }^{(56,57)}$. At baseline in this study, many patients had undergone previous surgery and/or had ongoing, significant symptoms despite use of conventional nasal steroids. However, comparatively few met this study's surgical indicator criteria, particularly those without polyps. Nevertheless, treatment was associated with a substantial reduction in the proportion of participants, with or without polyps, meeting surgical-indicator criteria. Surgery is generally considered effective and is appropriate for many patients, but achieving disease control that delays or prevents surgery, or repeat surgery, may produce meaningful economic benefits.

EDS-FLU was generally well tolerated at the highest recommended dose and exhibited a safety profile consistent with previous intranasal corticosteroids that were studied for similar durations in similar populations ${ }^{(51,52)}$. The safety profile was also consistent with previous reports from double blind placebo-controlled studies $^{(39,40)}$. The majority of AEs were local, mild in severity, and did not increase in frequency or severity with longer duration of use. Most AEs observed in the nasal cavity resolved with continued use. No systemic AEs associated with systemic corticosteroid absorption, including glaucoma and subcapsular cataracts, were identified.

\section{Strengths and Limitations}

This is one of the largest studies conducted to date in patients with moderate-to-severe CRS (including both CRSwNP and CRSsNP) and is highly generalizable in the target clinical scenario: persistently symptomatic patients who have tried conventional intranasal steroids and/or had prior surgery. Because treatment was open label, there is potential for placebo effect or unknown bias, possibly mitigated by objective measurement of sinonasal inflammation. Regarding 'placebo effect' on objective polyp measures, a decrease in polyp grade in a placebo arm has been observed in studies with high baseline polyp grade scores (ie, consistent with polyps at or below the inferior turbinate, $\sim 4)$; however, studies with low baseline scores as in this study (ie, consistent with polyps in the middle meatus, $<3$ ) have reported that polyp grade actually increases with placebo treatment ${ }^{(39,42,51-54,58)}$. In this study, the CRSsNP population met CRS symptom criteria and underwent endoscopy at baseline, but confirmatory sinus imaging was not required.

\section{Conclusion}

In summary, this study finds that EDS-FLU was associated with improvement in objective evidence of sinonasal inflammation, including elimination of edema in a substantial proportion of patients, along with improved symptoms, QoL, and functioning. Similar benefits were reported in patients with or without NP at baseline and in patients switching directly from conventional inhaled nasal sprays. These data suggest that EDS-FLU is a helpful new tool in addressing this chronic and challenging disease and should be considered, before or after surgery, when optimizing medical care in patients with CRS.

\section{Acknowledgements}

This study was funded by Optinose. Optinose AS received grants from the Norwegian Research Council during the study and a tax deduction from SkatteFunn related to the study. Editorial assistance was provided by ECIR Medical Communications.

\section{Authorship contribution}

MRS, GCS, J.LR, and GP contributed to data collection, data interpretation, writing, and served as a study investigator. $\mathrm{KL}$ contributed to data collection, writing, and served as a study investigator. JCM and RAM contributed to literature search, study design, data collection, data analysis, data interpretation, and writing. JLC contributed to study design, data collection, data interpretation, and writing. PGD contributed to literature search, study design, data interpretation, and writing.

\section{Conflict of interest}

MRS reports serving on Speaker Bureau for Optinose during conduct of the study and outside the submitted work. GCS, JLR, GP have nothing to disclose. KL reports serving on a speaker bureau for Merck during conduct of study, and a speaker bureau for Teva, Optinose, Circassia, and AstraZeneca outside the submitted work; in addition, she reports involvement in a clinical trial for Genentech outside the submitted work. JCM, JLC, RAM, and PGD report being employees and shareholders of Optinose during the conduct of the study.

\section{References}

1. Hamilos DL. Chronic rhinosinusitis: epidemiology and medical management. J Allergy Clin Immunol. 2011;128(4):693-707.

2. Hastan D, Fokkens WJ, Bachert C, et al. Chronic rhinosinusitis in Europe--an under- estimated disease. A GA(2)LEN study. Allergy. 2011;66(9):1216-1223.

3. Hirsch AG, Stewart WF, Sundaresan AS, et al. Nasal and sinus symptoms and chronic rhinosinusitis in a population-based sample. Allergy. 2017;72(2):274-281.
4. Smith KA, Orlandi RR, Rudmik I. Cost of adult chronic rhinosinusitis: a systematic review. Laryngoscope. 2015;125(7):15471556

5. Fokkens WJ, Lund VJ, Mullol J, et al European position paper on rhinosinusi- 
tis and nasal polyps 2012. Rhinol Suppl. 2012;50(23):1-298.

6. Orlandi RR, Kingdom TT, Hwang PH, et al. International consensus statement on allergy and rhinology: rhinosinusitis. Int Forum Allergy Rhinol. 2016;6 Suppl 1:S22-209.

7. Uraguchi K, Kariya S, Makihara S, et al. Pulmonary function in patients with eosinophilic chronic rhinosinusitis. Auris Nasus Larynx. 2018;45(3):476-481.

8. Kelemence A, Abadoglu O, Gumus C, Berk S, Epozturk K, Akkurt I. The frequency of chronic rhinosinusitis/nasal polyp in COPD and its effect on the severity of COPD. COPD. 2011;8(1):8-12.

9. Soler ZM, Wittenberg E, Schlosser RJ, Mace JC, Smith TL. Health state utility values in patients undergoing endoscopic sinus surgery. Laryngoscope. 2011;121(12):26722678.

10. Gliklich RE, Metson R. The health impact of chronic sinusitis in patients seeking otolaryngologic care. Otolaryngol Head Neck Surg. 1995;113(1):104-109.

11. Lam K, Schleimer R, Kern RC. The etiology and pathogenesis of chronic rhinosinusitis: a review of current hypotheses. Curr Allergy Asthma Rep. 2015;15(7):41-015-0540-2.

12. Djupesland PG, Skretting A. Nasal deposition and clearance in man: comparison of a bidirectional powder device and a traditional liquid spray pump. J Aerosol Med Pulm Drug Deliv. 2012;25(5):280-289.

13. Weber R, Keerl R, Radziwill R, et al. Videoendoscopic analysis of nasal steroid distribution. Rhinology. 1999;37(2):69-73.

14. DeMarcantonio MA, Han JK. Nasal polyps: pathogenesis and treatment implications. Otolaryngol Clin North Am. 2011;44(3):68595, ix.

15. Akdis CA, Bachert $C$, Cingi $C$, et al. Endotypes and phenotypes of chronic rhinosinusitis: a PRACTALL document of the European Academy of Allergy and Clinical Immunology and the American Academy of Allergy, Asthma \& Immunology. J Allergy Clin Immunol. 2013;131(6):1479-1490.

16. Hull BP, Chandra RK. Refractory chronic rhinosinusitis with nasal polyposis Otolaryngol Clin North Am. 2017;50(1): 61-81.

17. Larsen PL, Tos M. Origin of nasal polyps: an endoscopic autopsy study. Laryngoscope. 2004;114(4):710-719.

18. Becker SS. Surgical management of polyps in the treatment of nasal airway obstruction. Otolaryngol Clin North Am. 2009:42(2):377-85, x.

19. Kennedy P, Bassiouni A, Psaltis A, Antisdel J, Brunworth J. Avascular necrosis after oral corticosteroids in otolaryngology: case report and review of the literature. Allergy Rhinol (Providence). 2016;7(1):50-54.

20. Waljee AK, Rogers MA, Lin P, et al. Short term use of oral corticosteroids and related harms among adults in the United States: population based cohort study. BMJ. 2017;357:j1415.

21. Van Zele T, Gevaert P, Holtappels G, et al.
Oral steroids and doxycycline: two different approaches to treat nasal polyps. J Allergy Clin Immunol. 2010;125(5):1069-1076.e4.

22. Vaidyanathan $S$, Barnes $M$, Williamson $P$, Hopkinson P, Donnan PT, Lipworth B. Treatment of chronic rhinosinusitis with nasal polyposis with oral steroids followed by topical steroids: a randomized trial. Ann Intern Med. 201 1;154(5):293-302.

23. Aggarwal R, Cardozo A, Homer JJ. The assessment of topical nasal drug distribution. Clin Otolaryngol Allied Sci. 2004;29(3):201-205.

24. Laube BL. Devices for aerosol delivery to treat sinusitis. J Aerosol Med. 2007;20 Suppl 1:S5-17; discussion S17-8.

25. Djupesland PG. Nasal drug delivery devices: characteristics and performance in a clinical perspective-a review. Drug Deliv Transl Res. 2013;3(1):42-62

26. Merkus P, Ebbens FA, Muller B, Fokkens WJ. The 'best method' of topical nasal drug delivery: comparison of seven techniques. Rhinology. 2006;44(2):102-107.

27. Dijkstra MD, Ebbens FA, Poublon RM Fokkens WJ. Fluticasone propionate aqueous nasal spray does not influence the recurrence rate of chronic rhinosinusitis and nasal polyps 1 year after functional endoscopic sinus surgery. Clin Exp Allergy. 2004;34(9):1395-1400.

28. Baguley $C$, Brownlow A, Yeung $K$, Pratt $E_{i}$ Sacks R, Harvey R. The fate of chronic rhinosinusitis sufferers after maximal medical therapy. Int Forum Allergy Rhinol. 2014;4(7):525-532.

29. Bhattacharyya N. Incremental health care utilization and expenditures for chronic rhinosinusitis in the United States. Ann Otol Rhinol Laryngol. 2011;120(7):423-427.

30. Palmer JN, Messina JC, Biletch R, Grosel K, Mahmoud RA. A cross-sectional, population-based survey of U.S. adults with symptoms of chronic rhinosinusitis. Allergy Asthma Proc. 2019;40(1):48-56.

31. Kennedy DW. Additional options in chronic rhinosinusitis management [published online ahead of print, 2018 Jul 20]. Int Forum Allergy Rhinol. 2018;10.1002/ alr.22188. doi:10.1002/alr.22188

32. Harvey RJ, Debnath N, Srubiski A, et al. Fluid residuals and drug exposure in nasal irrigation. Otolaryngol Head Neck Surg. 2009:141:757-761

33. Merkus P, Ebbens FA, Muller B, Fokkens WJ. Influence of anatomy and head position on intranasal drug deposition. Eur Arch Otorhinolaryngol. 2006;263(9):827-832.

34. Djupesland PG, VIckova I, Hewson G. Impact of baseline nasal polyp size and previous surgery on efficacy of fluticasone delivered with a novel device: a subgroup analysis. Am J Rhinol Allergy. 2010;24(4):291-295.

35. Hansen FS, Djupesland PG, Fokkens WJ Preliminary efficacy of fluticasone delivered by a novel device in recalcitrant chronic rhinosinusitis. Rhinology. 2010;48(3):292-299.

36. Exhalation Delivery Systems. Optinose website. https://www.optinose.com/exha- lation-delivery-systems/technical-overview. Accessed November 18, 2019

37. XHANCE ${ }^{T M}$ (fluticasone propionate) [prescribing information]. Yardley, PA: OptiNose US, Inc; 2017.

38. Messina JC, Offman E, Carothers JL, Mahmoud RA. A Randomized Comparison of the Pharmacokinetics and Bioavailability of Fluticasone Propionate Delivered via Xhance ${ }^{\oplus}$ Exhalation Delivery System Versus Flonase $^{\circledR}$ Nasal Spray and Flovent ${ }^{\oplus}$ HFA Inhalational Aerosol. Clin Ther. 2019. pii: S0149-2918(19)30491-6. doi: 10.1016/j. clinthera.2019.09.013. [Epub ahead of print]

39. Leopold DA, Elkayam D, Messina JC, KosikGonzalez C, Djupesland PG, Mahmoud RA. NAVIGATE II: randomized, double-blind trial of the exhalation delivery system with fluticasone (EDS-FLU) for nasal polyposis. J Allergy Clin Immunol. 2019;143(1):126-134. e5.

40. Sindwani R, Han JK, Soteres DF, et al. NAVIGATE I: randomized, placebo-controlled, double-blind trial of the exhalation delivery system with fluticasone for chronic rhinosinusitis with nasal polyps. Am J Rhinol Allergy. 2019:33(1):69-82.

41. Palmer JN, Jacobson KW, Messina JC, KosikGonzalez C, Djupesland PG, Mahmoud RA. EXHANCE-12: 1-year study of the exhalation delivery system with fluticasone (EDS-FLU) in chronic rhinosinusitis. Int Forum Allergy Rhinol. 2018;8(8):869-876

42. VIckova I, Navratil P, Kana R, Pavlicek P, Chrbolka P, Djupesland PG. Effective treatment of mild-to-moderate nasal polyposis with fluticasone delivered by a novel device. Rhinology. 2009;47(4):419-426.

43. Sino-Nasal Outcome Test (SNOT-22). Washington University, St. Louis, MO, U.S. 2006.

44. Hopkins C, Gillett S, Slack R, Lund VJ, Browne JP. Psychometric validity of the 22-item Sinonasal Outcome Test. Clin Otolaryngol. 2009;34(5):447-454

45. Phillips KM, Hoehle LP, Caradonna DS, Gray ST, Sedaghat AR. Minimal clinically important difference for the 22-item Sinonasal Outcome Test in medically managed patients with chronic rhinosinusitis. Clin Otolaryngol. 2018.

46. Lildholdt $\mathrm{T}$, Rundcrantz $\mathrm{H}$, Lindqvist $\mathrm{N}$. Efficacy of topical corticosteroid powder for nasal polyps: a double-blind, placebo-controlled study of budesonide. Clin Otolaryngol Allied Sci. 1995;20(1):26-30.

47. Lund VJ, Kennedy DW. Staging for rhinosinusitis. Otolaryngol Head Neck Surg. 1997;117(3 Pt 2):S35-40.

48. Amirfeyz R, Pentlow A, Foote J, Leslie I. Assessing the clinical significance of change scores following carpal tunnel surgery. Int Orthop. 2009;33(1):181-185.

49. Hurst $H$, Bolton J. Assessing the clinical significance of change scores recorded on subjective outcome measures. J Manipulative Physiol Ther. 2004;27(1):26-35.

50. Kamper SJ, Maher CG, Mackay G. Global rating of change scales: a review of strengths 
and weaknesses and considerations for design. J Man Manip Ther. 2009;17(3):163 170.

51. Small CB, Hernandez J, Reyes A, et al. Efficacy and safety of mometasone furoate nasal spray in nasal polyposis. J Allergy Clin Immunol. 2005;116(6):1275-1281.

52. Stjarne $P$, Mosges $R$, Jorissen $M$, et al. A randomized controlled trial of mometasone furoate nasal spray for the treatment of nasal polyposis. Arch Otolaryngol Head Neck Surg. 2006;132(2):179-185

53. Chong LY, Head K, Hopkins C, Philpott C, Schilder AG, Burton MJ. Intranasal steroids versus placebo or no intervention for chronic rhinosinusitis. Cochrane Database Syst Rev. 2016;26(4):CD011996.

54. Zhou B, He G, Liang J, et al. Mometasone furoate nasal spray in the treatment of nasal polyposis in Chinese patients: a doubleblind, randomized, placebo-controlled trial.
Int Forum Allergy Rhinol. 2016;6(1):88-94.

55. Han J, Mahmoud R, Messina J, Carothers J, Djupesland P. Interpretations of nasal polyp grade change scores differ significantly between studies. Presented at: 63rd Annual American Rhinologic Society Meeting; September 8-9, 2017; Chicago, IL.

56. Bhattacharyya N. Ambulatory sinus and nasal surgery in the United States: demographics and perioperative outcomes. Laryngoscope. 2010;120(3):635-638.

57. Rudmik L, Soler ZM, Hopkins C, et al. Defining appropriateness criteria for endoscopic sinus surgery during management of uncomplicated adult chronic rhinosinusitis: a RAND/UCLA appropriateness study. Int Forum Allergy Rhinol. 2016;6(6):557-567.

58. Vendelo Johansen L, Illum P, Kristensen S, Winther L, Vang Petersen S, Synnerstad B. The effect of budesonide (Rhinocort) in the treatment of small and medium-sized nasal polyps. Clin Otolaryngol Allied Sci. 1993;18(6):524-527.

59. Palmer JN, Jacobson KW, Messina JC, KosikGonzalez C, Djupesland PG, Mahmoud RA. EXHANCE-12: 1-year study of the exhalation delivery system with fluticasone (EDS-FLU) in chronic rhinosinusitis. Int Forum Allergy Rhinol. 2018;00:1-8.

Mandel R. Sher, MD

Sher Allergy Specialist

11200 Seminole Blvd

Largo, FL 33778

USA

Tel: +1-727-397-8557

E-mail: DrMRSher@aol.com 